\title{
A perspectiva educativa nos laboratórios de pesquisa: um diálogo entre a escola básica e a universidade
}

Francisca Vânia Pereira Rodrigues

Secretaria Municipal de Educação

Viçosa - CE

Roseline Beatriz Strieder ${ }^{1}$

Instituto de Física - Universidade de Brasília

Rafael Cabreira Gomes ${ }^{1}$

Departamento de Física - Universidade Federal de Santa Catarina

Jerome Depeyrot ${ }^{1}$

Instituto de Física - Universidade de Brasília

Brasília - DF

Graciella Watanabe

Centro de Ciências Naturais e Humanas - Universidade Federal do ABC

Santo André - SP

\section{Resumo}

As pesquisas em ensino de ciências têm apontado a necessidade de incorporar, na formação dos alunos da educação básica, experiências educacionais que ultrapassem atividades formais, destinadas aos contextos das salas de aula. Partindo desse pressuposto, neste artigo, discutimos desafios e potencialidades associados às visitas aos laboratórios de pesquisa. Em especial, investigamos como atividades propostas por docentes da escola básica e ações de divulgar de cientistas, quando complementares, podem promover reflexões sobre o saber e o fazer científico. Para tanto, são trabalhados aspectos quantitativos e qualitativos associados às respostas e produções de alunos participantes de atividades de divulgação cientifica realizadas em um laboratório de nanotecnologia, articuladas a ações que ocorreram

\footnotetext{
${ }^{+}$The educational perspective in research laboratories: a dialogue between elementary school and university

* Recebido: março de 2020. Aceito: junho de 2020.

${ }^{1}$ E-mails: vaniafpr@gmail.com; roseline@unb.br; r.cabreira.gomes@ufsc.br; jerome.depeyrot@gmail.com; graciewat@gmail.com
} 
no contexto formal de educação. Dentre os resultados, destacamos desafios associados à superação da suposta neutralidade da ciência por parte dos alunos, em especial, da visão salvacionista enfatizada neste artigo. Defendemos que é preciso aumentar a frequência de atividades que promovam discussões sobre a produção e apropriação do conhecimento científico e tecnológico, sempre na perspectiva de articular escola básica e universidade, reconhecendo que ambas são responsáveis pela formação de cidadãos.

Palavras-chave: Ciência-Tecnologia-Sociedade; Cientistas; Divulgação Cientifica.

\begin{abstract}
The researches on science teaching have showed the importance of inclusion of educational experiences on the basic education. To go further, these experiences must overcome the normal activities designed for the conventional classes' context. By starting from that assumption, in this paper we discuss the potential and challenges related to the scientific research labs visit. Particularly, we investigate as the activities proposed by teachers and divulgation actions of researchers, may promote learning and reflections about the science. For that, we analyze qualitative and quantitative aspects related to both quizzes and educational productions proposed to the secondary education students which participate to the scientific divulgation activities performed on the nanotechnology laboratory. Among the results, we highlight the challenges in the overcoming of the vision of non-neutrality of science by the students, especially the salvationist perspective. In such way, we defend the increasing of frequency of activities promoting discussion about production and appropriation of scientific and technological knowledge. Such activities must be always performed between both school and university, recognizing the responsibility of both in the citizen formation.
\end{abstract}

Keywords: Science-Technology-Society; Scientist; Scientific Divulgation. 


\section{Introdução}

Atividades de divulgação científica vêm sendo tratadas há muito tempo, seja em termos de ações na perspectiva literária (MORA, 2003) quanto em atividades associadas a centros e museus de ciências (WAGENSBERG, 2005; OLIVEIRA et. al., 2017). Todos esses trabalhos, de certo modo, apontam para a importância de se construir uma cultura científica na sociedade, facilitando a aproximação com o saber científico e a elaboração de visões mais críticas e atualizadas sobre o tema (ENTRADAS et. al., 2019; BEAUNE, 1988).

Pesquisas atuais buscam implementar a esse debate aspectos do ensinar ciências no contexto escolar, na perspectiva de beneficiar a aprendizagem científica dos estudantes por meio da inserção da divulgação científica em atividades pedagógicas (LIMA; GIORDAN, 2018). Essa discussão, iniciada nos anos 80/90 no Brasil (SALÉM; KAWAMURA, 1996), indica que o maior ganho em trazer outros materiais para a sala de aula, como textos e práticas da comunicação científica, é a possibilidade de os alunos terem experiências que sejam próximas ao discurso do professor e contextualizadas por outras fontes.

Essas experiências, por sua vez, também, podem ser reconhecidas como importantes ou mais significativas para os alunos quando os cientistas propõem aproximações por meio de práticas de divulgar associadas aos seus laboratórios de pesquisa (WATANABE, 2017). Reconhece-se que essa aproximação dos alunos do ensino médio de ações nas universidades tende a conduzir experiências que lhes permitem adquirir maior confiança e engajamento nos discursos científicos, visto que os temas são vivenciados nessas interações de divulgação. Isso se deve ao fato de estudantes perceberem o trabalho do cientista como algo próximo de sua realidade e que pode ser considerado como um aumento do seu capital cultural (e científico) WATANABE, 2017).

O que de novo se tem percebido é a necessidade de cientistas fazerem ações de divulgar como prática articulada a aspectos educacionais, assim como reconhecendo essas propostas como impactando a formação para a cultura científica dos alunos. Isso implica entender, por exemplo, que a compreensão pública da ciência é influenciada pela experiência vivenciada na aproximação com os cientistas (MERINO; NAVARRO, 2019). Assim, ao tratarmos da interação entre a universidade e a escola, entre o laboratório científico e a sala de aula, é preciso retomarmos objetivos pedagógicos e compreendermos os limites de cada um deles, para posteriormente reconhecer suas potências quando se aproximam.

Um empecilho para que isso ocorra, de certo modo, recai sobre a dificuldade dos cientistas que fazem a divulgação científica reconhecerem seus limites e construírem atividades que efetivamente apresentam o processo do "fazer ciência". Em geral, ao tratarem ações de divulgar, físicos, químicos e biólogos, propõem narrativas que evitam apontar percalços e fracassos do trabalho que produzem. Os discursos para que essa temática não seja apresentada, na maioria dos casos, é justificada pela relativa complexidade da abordagem, falta de tempo para selecionar os conhecimentos que "realmente importam" ou pela necessidade de legitimar um saber e uma atividade profissional desprestigiada socialmente 
(HU et. al., 2018). Em outras palavras, nessa perspectiva, ao apontar os erros, contribuiríamos para aumentar ainda mais o afastamento do público sobre os temas da ciência e seus interesses pelas práticas dos cientistas (JACOBI, 1999).

Os resultados gerados por esse tipo de construção biográfica da ciência refletem, no contexto escolar (e social como um todo), em constantes perspectivas salvacionistas da ciência (AULER; DELIZOICOV, 2001) que alunos e professores possuem. Esse mito salvacionista, que recai no saber científico e tecnológico, acaba por ser incorporado ao consumo irrefletido dos produtos e gera o desencadeamento de informações sobre temáticas científicas, por vezes, equivocadas.

O que se pode observar é que existe um embate entre cientistas e educadores e/ou divulgadores que leva a dúvidas sobre "o que" e "como" abordar a ciência por cientistas para alunos do ensino médio (e para o público geral). Se é possível reconhecer um meio termo nesse processo, esse seria a constante negociação entre professores e cientistas, mediados pelos pesquisadores em ensino de ciências, para mobilizar os diferentes interesses desse processo. A construção, portanto, ocorre na fronteira entre dois mundos ou campos (WATANABE, 2017) e que são permeados por um conjunto de pensamentos que ora se aproximam e ora se afastam, em um processo constante de reflexão. Partindo desse debate que o presente artigo se propõe a investigar: Quais impactos educacionais podem ser percebidos em uma visita a um laboratório científico quando professor e cientista conduzem ações educacionais em conjunto e, em que medida, pode-se reconhecer indícios da superação da visão salvacionista da ciência?

A busca por respostas a esse questionamento foi produzida na tentativa de reconhecer como alunos da educação básica, ao adentrarem um laboratório de pesquisa, associados aos estudos e atividades em sala de aula, podem construir visões sobre a ciência que superem (ou não) a ideia do seu mito salvacionista. Principalmente, reconhecendo que a superação de tais práticas só pode obter sucesso quando questionados e colocados em contraponto às ideias que permeiam a ciência e a tecnologia, em especial, nas questões científicas e sociais. Portanto, a Educação CTS (Ciência-Tecnologia-Sociedade) torna-se a perspectiva epistemológica que mobiliza as reflexões teóricas e analíticas do presente trabalho. Assim, este artigo se divide em:

- Destacar o papel da Educação CTS como perspectiva orientadora de ações que envolvem visitas a laboratórios;

- Discutir maneiras pelas quais as práticas em laboratórios podem ser tratadas em contextos de sala de aula;

- Apresentar visitas em laboratórios científicos monitoradas por cientistas como potenciais para aproximar os alunos de educação básica da prática científica;

- Reconhecer as dimensões de influências das práticas educativas na formação ou superação das ideias dos alunos sobre ciências. 
Pretende-se com esse debate dar subsídios aos pesquisadores e professores da escola básica para reconhecerem e produzirem, a partir de suas realidades, espaços de diálogo e de construção de ações entre a universidade e a escola, possibilitando a co-participação na responsabilidade formativa das alunas e alunos.

\section{Pressupostos teóricos}

Diante de agravos e desastres mundiais envolvendo o desenvolvimento científicotecnológico, como a guerra do Vietnã, a guerra fria, as armas químicas e biológicas, as catástrofes ambientais e as armas nucleares, intensificou-se a preocupação de muitos intelectuais e também militantes com as consequências dessas produções para o meio ambiente e para a sociedade. Eles passaram a questionar o modelo linear de progresso que afirma que tais avanços estão ligados, automaticamente, ao bem-estar social e à melhoria da qualidade de vida de todas as pessoas. Com isso, no final da década de 1960 e início de 1970, na Europa e na América do Norte, surgiu o denominado Movimento CTS que defende a democratização das decisões relacionadas ao desenvolvimento científico-tecnológico (GARCIA; CEREZO; LUJÀN, 1996). Nessa mesma época, na América Latina, fortaleceramse as críticas sobre o modelo de política científica e tecnológica adotado nesses países, por ser contrário às necessidades regionais. Atualmente, essas discussões são reconhecidas como pertencentes ao Pensamento Latino-Americano em CTS (PLACTS) (DAGNINO; THOMAS; DAVYT; 2003).

Esses estudos, em especial, os presentes na Europa e na América do Norte, repercutiram para o contexto educacional brasileiro, onde assumiram diferentes propósitos e perspectivas de trabalho (STRIEDER; KAWAMURA, 2017). Neste artigo, em particular, assumimos como objetivos da educação CTS o desenvolvimento de compromissos sociais. Ou seja, buscamos contribuir para a formação de uma sociedade apta a lidar com problemas reais, de diferentes naturezas; com condições de fazer uma leitura crítica da realidade que está marcada por desequilíbrios sociais, políticos, éticos, culturais e ambientais, associados ao desenvolvimento científico-tecnológico (AULER, 2002; STRIEDER; KAWAMURA, 2017). Essa perspectiva, portanto, apresenta elementos comuns aos pressupostos educacionais de Paulo Freire (1979; 1987), no sentido em que visa investigar a realidade de forma a identificar caminhos para sua transformação. Também, como destacam Strieder e Kawamura (2017), implica discutir questões associadas à racionalidade científica, ao desenvolvimento tecnológico e à participação social. Em concreto:

(..) uma educação CTS em consonância com essa perspectiva implica, por exemplo, discutir as limitações do conhecimento científico para compreender e resolver os problemas sociais; enfatizar a importância de a sociedade almejar outro modelo de desenvolvimento, que busque satisfazer as necessidades básicas de uma determinada população e não gerar lucro econômico; e, buscar uma cultura de participação no âmbito das políticas públicas, na definição de objetivos, meios para 
alcançá-los e maneiras de controlar sua implementação (STRIEDER; KAWAMURA, 2017, p. 47).

Sua efetiva inserção na educação básica está associada a um outro olhar para o currículo escolar, que deixa de focar na adequação dos jovens para uma vida social e produtiva bem estabelecida e passa a ter a função social de prepará-los para o enfrentamento de novos problemas e para a definição de rumos para si e para a sociedade com a qual se encontram.

Isso perpassa a construção de uma visão de ciência e tecnologia não neutras e a superação de três mitos, associados, segundo Auler (2002) à superioridade do modelo de decisões tecnocráticas, à perspectiva salvacionista da ciência e tecnologia e ao determinismo tecnológico. De acordo com esses mitos (respectivamente), quem deve tomar as decisões referentes a questões científico-tecnológicas são, somente, técnicos especialistas; os problemas da humanidade serão solucionados em algum momento pelos avanços científicotecnológicos; e, o desenvolvimento científico-tecnológico é irreversível e arrasta atrás de si o desenvolvimento social.

Essa visão, para o autor, pode ser problematizada a partir de quatro dimensões que envolvem (i) o direcionamento dado à atividade científico-tecnológica; (ii) a apropriação do conhecimento científico-tecnológico; (iii) o processo de produção do conhecimento científico e (iv) o aparato ou produto tecnológico. Segundo Auler, ciência e tecnologia não podem ser consideradas neutras porque o processo de produção e o direcionamento não resultam apenas dos tradicionais fatores epistêmicos (lógica e experiência), eles são influenciados por decisões políticas. Sendo assim, o produto incorpora interesses e desejos de sociedades ou de grupos sociais hegemônicos e, além disso, sua apropriação não ocorre de forma equitativa. Permeando esse discurso, está o questionamento da concepção tradicional, linear e tecnocrática de progresso e a defesa pela formulação de políticas públicas efetivamente democráticas.

Ainda no que diz respeito à neutralidade da ciência e da tecnologia, destacamos o estudo de Oliveira (2003). Inspirado nos trabalhos de Hugh Lacey, esse autor coloca que a neutralidade da ciência está associada a três pontos de vista, que devem ser questionados: (i) Tese da neutralidade temática: a ciência é neutra porque o direcionamento da pesquisa científica, isto é, a escolha dos temas e problemas a serem investigados, responde apenas ao interesse em desenvolver o conhecimento como um fim em si mesmo; (ii) Tese da neutralidade metodológica: a ciência é neutra porque procede de acordo com o método científico, segundo o qual a escolha racional entre as teorias não deve envolver, e de maneira geral não tem envolvido valores sociais. (iii) Tese da neutralidade factual: a ciência é neutra porque não envolve juízos de valor; ela apenas descreve a realidade, sem fazer prescrições; suas proposições são puramente factuais.

Seguindo esses pressupostos, Rosa e Strieder (2019) colocam que as práticas educativas fundamentadas na educação CTS deveriam se preocupar em verbalizar 
silenciamentos associados à neutralidade da ciência e da tecnologia. Dentre esses silenciamentos as autoras destacam os relacionados à origem, concepção e direcionamento da ciência e tecnologia; os conhecimentos mobilizados para a resolução de problemas sociais; e, as questões valorativas internalizadas na ciência e tecnologia.

A nosso ver, para essa verbalização e superação dos mitos mencionados e a formação de uma visão ampliada da ciência e da tecnologia é preciso que os alunos tenham a oportunidade de problematizar a atividade científico-tecnológica a partir de situações reais e in loco. É com essa preocupação que a intervenção descrita a seguir foi desenvolvida e analisada,seguindo os pressupostos defendidos na introdução deste trabalho.

\section{Contexto e metodologia}

A presente investigação foi desenvolvida com 54 alunos (duas turmas) do $3^{\circ}$ ano do Ensino Médio de uma escola pública localizada em Planaltina, cidade satélite de Brasília. Essa escola atende o ensino fundamental (séries finais e EJA) e o ensino médio (regular e EJA). Trata-se de uma escola que recebe muitos alunos da zona rural, como a maioria dos estudantes que participaram desta pesquisa, embora não esteja inserida nesse contexto.

Com esse grupo de alunos foram realizadas duas ações complementares: (i) inserções pontuais do tema nanociência em cinco aulas de Física, contemplando o conteúdo programático previsto para a série, e, (ii) uma visita guiada ao Laboratório de Fluidos Complexos (LFC) da Universidade de Brasília (UnB), onde se investiga diversos tipos de materiais nanométricos e suas aplicações.

Além dos alunos, participaram da investigação, uma professora da educação básica, mestranda em Ensino de Física; três professores universitários, sendo duas doutoras em Ensino de Física e um doutor em Física; e um pesquisador e doutor em Física. Esses dois últimos pertencentes ao LFC. Além deles, pós-graduandos, vinculados ao LFC, participaram da execução da visita, apresentando as dependências do laboratório para os alunos da educação básica, como será descrito a seguir.

Antes dessa descrição, é importante esclarecermos que este trabalho faz parte da pesquisa de mestrado da referida professora de educação básica, que investigou limites e potencialidades destas ações para que os alunos compreendessem aspectos associados à temática da nanociência (a exemplo de características da matéria, métodos/técnicas de produção e observação, aplicações e usos, implicações e preocupações). Assim, a parte referente às aulas foi elaborada pela professora e sua orientadora. A visita, por sua vez, é uma atividade realizada pelo laboratório há alguns anos, sempre por demanda de professores (de escolas e/ou da universidade). Neste caso, ela foi adaptada para atender a alguns interesses da pesquisa de mestrado, em especial, as discussões sobre produção e apropriação do conhecimento científico e tecnológico. Solicitou-se que ao longo da visita fossem enfatizadas questões associadas ao cotidiano de um laboratório de pesquisa cientifica, incluindo, por exemplo, discussões sobre a definição dos problemas pesquisados, os financiamentos das 
pesquisas e como esses recursos são angariados. Como será detalhado a seguir, essas questões foram abordadas, principalmente, na palestra realizada na abertura da visita, proferida pelo pesquisador doutor em Física.

Descrevendo melhor as ações na escola, na primeira aula os alunos foram convidados a refletir e discutir sobre potencialidades e incertezas associadas à nanociência e nanotecnologia, expressando seus conhecimentos a respeito do tema. A intenção, nesse momento, era problematizar as compreensões dos alunos sobre o tema, mobilizando-os a estudarem o assunto. Em seguida foi feita uma discussão sobre o desenvolvimento da nanociência e da nanotecnologia, criando-se uma linha do tempo com fatos históricos importantes relacionados ao tema. Além disso, foi apresentado o significado do prefixo nano e escalas de comprimento, situando o nanômetro e comparando materiais e objetos. Depois disso, foi solicitada a realização de uma pesquisa sobre o tema - busca e leitura de textos disponíveis na internet. Os resultados dessa pesquisa foram discutidos na segunda aula e abarcaram exemplos de pesquisas e produtos usando a nanotecnologia e seus impactos na sociedade (incluindo o meio ambiente); as características e propriedades da matéria na escala nano e a manipulação átomo a átomo; e, riscos e incertezas em torno da temática.

As aulas que seguem foram usadas para aprofundar as discussões sobre o tema. $\mathrm{Na}$ terceira aula, foram enfatizados conceitos físicos relacionados ao assunto e pertencentes à grade curricular do $3^{\circ}$ ano da escola. Foram abordadas as propriedades da matéria em escala nanométrica com ênfase no magnetismo. Na quarta aula o foco esteve na discussão sobre a não neutralidade do desenvolvimento científico tecnológico, com ênfase em aspectos políticos, sociais e econômicos por trás desse desenvolvimento. Na quinta aula, os alunos foram reunidos em duplas, e depois disso foi solicitada a elaboração de uma narrativa, com previsão ficcionista, sobre nanociência e nanotecnologia e seus impactos na sociedade.

Ao final dessas intervenções pontuais os alunos visitaram as instalações do LFCUnB. Os principais objetivos dessa visita eram aproximar os alunos do cotidiano de um laboratório de pesquisa cientifica e propiciar a interação entre alunos e cientistas. Isso contribui para que os estudantes possam vivenciar um pouco da rotina dos cientistas, entedam o que eles fazem e para que possam tirar dúvidas sobre suas pesquisas.

A visita dos alunos ao LFC-UnB foi conduzida em duas etapas, a citar, palestra e visita guiada. No que concerne a palestra, primeiramente, foram apresentados exemplos de fenômenos de nanoescala encontrados na Natureza e que servem de inspiração para muitas das pesquisas científicas que buscam novos materiais. Depois disso foi feita uma pequena revisão sobre a evolução dos nanomateriais. Para tal, partiu-se da produção de pós finos de Ouro, descobertos na Idade Média, que eram usados nos vitrais das igrejas, cuja cor depende do tempo de maceração. Em outras palavras, mostramos que a cor do pó tem estreita relação com diâmetro da nanopartícula. Partindo disso, destacou-se que atualmente as aplicações de nanociência concernem várias áreas como o armazenamento de informação e o diagnóstico e tratamento de enfermidades. 
As características físicas diferenciadas dos nanomateriais foram explicadas comparando sua dimensionalidade a de micro objetos do nosso cotidiano. Essa comparação mostra que a razão superfície/volume dos nanomateriais é muito maior que a dos micro objetos, e dessa forma, é possível entender que as propriedades magnéticas, óticas e reatividade química desses materiais surge das ligações químicas na superfície que nem sempre são neutras e/ou estabilizadas.

O seminário estendeu-se também aos métodos de observação dos nanomateriais, como por exemplo, a Microscopia Eletrônica de Transmissão e a Difração de Raios X, evidenciando que neste último as características estruturais e morfológicas das nanopartículas são analisadas de forma indireta. Com efeito, foram apresentadas imagens e difratogramas de materiais sintetizados no LFC, discutindo aspectos como a estrutura cristalina e a forma das nanopartículas.

No sentido de contextualizar as informações gerais discutidas, foram exibidos resultados atuais de duas linhas de pesquisa do LFC. Estas referem-se a aplicações de nanopartículas tanto em sistemas biológicos (PILATI et. al., 2018), utilizadas como instrumento para cura de enfermidades, quanto na remoção de corantes de efluentes hídricos (CAMPOS et. al., 2019). É sabido que esses tópicos fascinam os estudantes, devido principalmente ao apelo de sustentabilidade, saúde e bem estar. Esses temas induziram debates e argumentações acaloradas por parte dos estudantes, dedicando-se essencialmente aos prós e contras da pesquisa científica. Como exemplos desses debates é possível citar: a discussão sobre a ética na utilização de animais como cobaias de pesquisas in vivo, ou ainda, a segurança contra contaminação do meio ambiente após a intervenção de nanomateriais.

A respeito das aplicações biológicas, a magneto hipertermia (MHT) foi apresentada como instrumento sinérgico para o tratamento oncológico. Para tal, mostrou-se que o incremento de temperatura local causado pela ação de um campo magnético alternado sobre nanopartículas magnéticas incorporadas a uma célula, pode causar a apoptosis/necrosis. Além da morte celular programada, esse efeito pode aumentar a eficiência dos tratamentos por quimioterapia e/ou radioterapia, devido à permeabilização forçada das membranas. A comunicação desses resultados foi feita pela apresentação de imagens de Microscopia Eletrônica de Varredura de células da linha celular BV-2 (macrofagos do sistema nervoso) com e sem a incorporação de nanopartículas, antes e depois da irradiação com campo magnético alternado, ressaltando os efeitos da MHT.

Em referência à segunda linha de pesquisa, primeiramente foi apresentado um ranking dos tipos de indústrias que mais degradam o meio ambiente, quais os tipos de contaminantes mais comuns e os efeitos decorrentes de seu descarte na natureza. A partir disso, ressaltamos que os metais pesados (indústria química) e os corantes (indústria têxtil e tintas) são alguns dos contaminantes mais prejudiciais. Além disso, explorou-se como as técnicas convencionais de remoção de contaminantes dos efluentes hídricos industriais funcionam e o panorama para utilização de nanopartículas magnéticas nesse sentido. Para 
elucidar o mecanismo de funcionamento dessa aplicação foram apresentados vídeos de experimentos em que uma pequena quantidade de nanopartículas magnéticas é adicionada a uma solução de corante direct yellow 12 (DY12) e, logo depois, com a ajuda de um ímã, a solução torna-se completamente transparente. Em outras palavras, a ação do campo magnético atrai as nanopartículas, e consequentemente, as moléculas DY12 adsorvidas em sua superfície.

Após a palestra, o conjunto de alunos foi conduzido à segunda parte da visita que consta na apresentação das instalações do LFC. Para isso eles foram divididos em cinco pequenos grupos, cada qual acompanhado por um pós-graduando. Cada um desses grupos se deslocou para uma sala diferente do LFC, onde estão instalados diferentes instrumentos científicos. Ali os pesquisadores apresentaram resumidamente esses equipamentos, seus temas de pesquisa e realizaram experimentos simples, que mostram as particularidades dos materiais investigados. Após isso, foi feita uma rotação para que todos os grupos fossem contemplados. A citar, os alunos conheceram pesquisas em síntese química de nanomateriais, espalhamento de raios $\mathrm{X}$ em baixo ângulo, propriedades magnéticas, propriedades óticas e remoção de contaminantes.

Ao final da visita, os grupos foram reunidos para considerações finais. Nesse momento, foram discutidas questões associadas aos financiamentos das pesquisas e como esses recursos são angariados. Sobre isso, destacamos que as investigações realizadas no laboratório são financiadas, principalmente, pelo governo brasileiro. Depois disso, foi pedido que os alunos avaliassem a visita respondendo a um questionário. Nesse questionário, além das perguntas de avaliação da visita, foram inseridas questões que permitem avaliar seu perfil econômico, sócio-cultural e de opinião sobre o papel do cientista na sociedade.

Ainda, depois da visita guiada e novamente em sala de aula, foi solicitado uma última atividade aos alunos. Divididos em 7 grupos, cada um elaborou uma história em quadrinhos contemplando o tema: Como você imagina o planeta Terra daqui a 50 anos e a vida dos seres humanos a partir do uso da nanociência e nanotecnologia?

As respostas ao questionário e as produções dos alunos foram analisadas seguindo elementos da Análise de Conteúdo (BARDIN, 2008). Sendo assim, procedeu-se inicialmente à organização dos dados; em seguida à sua codificação e categorização e, por fim, ao tratamento e à interpretação dos resultados, que serão apresentados a seguir.

\section{Resultados e discussões}

Os resultados estão organizados em três categorias: contexto sociocultural e econômico dos sujeitos, avaliação da visita e compreensões sobre o trabalho do cientista. A primeira categoria está associada aos parâmetros sociais, conforme aponta Beaune (1988) sobre a importância da formação do capital cultural do público para a compreensão dos aparatos culturais que permeiam a divulgação científica. Assim, buscou-se entender a formação dos pais como fator determinante para estabelecer a cultura global dos alunos que 
participaram das atividades, entendendo, por sua vez, que o acesso às atividades culturais e científicas se dão, também, no núcleo familiar. Na categoria avaliação da visita, optou-se por tratar os dados conforme interesses e críticas associadas à experiência na atividade proposta. Essa categoria visa reconhecer em que medida o público participante pode ser considerado parte do processo de produção das ações de divulgar (WAGENSBERG, 2005). Por fim, a última categoria apresentada se associa à compreensão sobre o trabalho do cientista, cujo objetivo é compreender, em diálogo às diferentes perspectivas envolvidas na prática de divulgar, sobre elementos do fazer da ciência que podem ser percebidos nessas ações. Em especial, a categoria tem o objetivo de tratar elementos associados à perspectiva da educação CTS ao reconhecer possíveis engajamentos ou preocupações sociais que permeiam o trabalho do cientista.

\section{IV.1 Contexto sócio cultural e econômico dos sujeitos}

Ao analisar os impactos educacionais em uma visita a um laboratório de pesquisa, torna-se necessário reconhecer que as experiências vivenciadas por cada um dos estudantes não se limitam à interação com os cientistas, mas, também, à trajetória social de cada pesquisado. Nesse contexto, a própria natureza da ação não pode ser compreendida como universal em termos dos seus resultados, mas marcadamente como parte da tríade educação, sociedade e ciência. Partindo desse pressuposto que esta categoria se justifica como elemento de análise para construir um arcabouçou sociocultural e econômico que vise contextualizar o perfil do grupo analisado e seus possíveis impactos na formação dos alunos.

Dessa forma, a Fig. 1(a) apresenta o perfil educacional médio dos pais dos estudantes. Nota-se que a maioria se concentra entre fundamental incompleto e médio completo. Para entender essa particularidade buscamos informações na base de dados do IBGE, mais especificamente para adultos acima de 25 anos. Os dados regionais confirmam o caráter transitório do Distrito Federal, caracterizado por funcionários públicos das esferas do governo (com ensino superior), que migraram de diversas áreas do Brasil. Logo, notamos que o perfil de escolaridade dos pais tem mais coerência com as médias nacionais, característica que enfatiza uma realidade nacional à região da escola.

Assim, em termos sociais, a formação cultural dos participantes está próxima a de outros públicos da divulgação científica. Em especial, pode-se reconhecer que a formação escolar dos pais não dá indícios de que os estudantes tenham aproximações com a cultura científica sob sua dimensão formal, ou seja, de conhecimento ou reconhecimento dos espaços de formação dos cientistas como a universidade ou centros de pesquisa (NOGUEIRA; NOGUEIRA, 2007). 


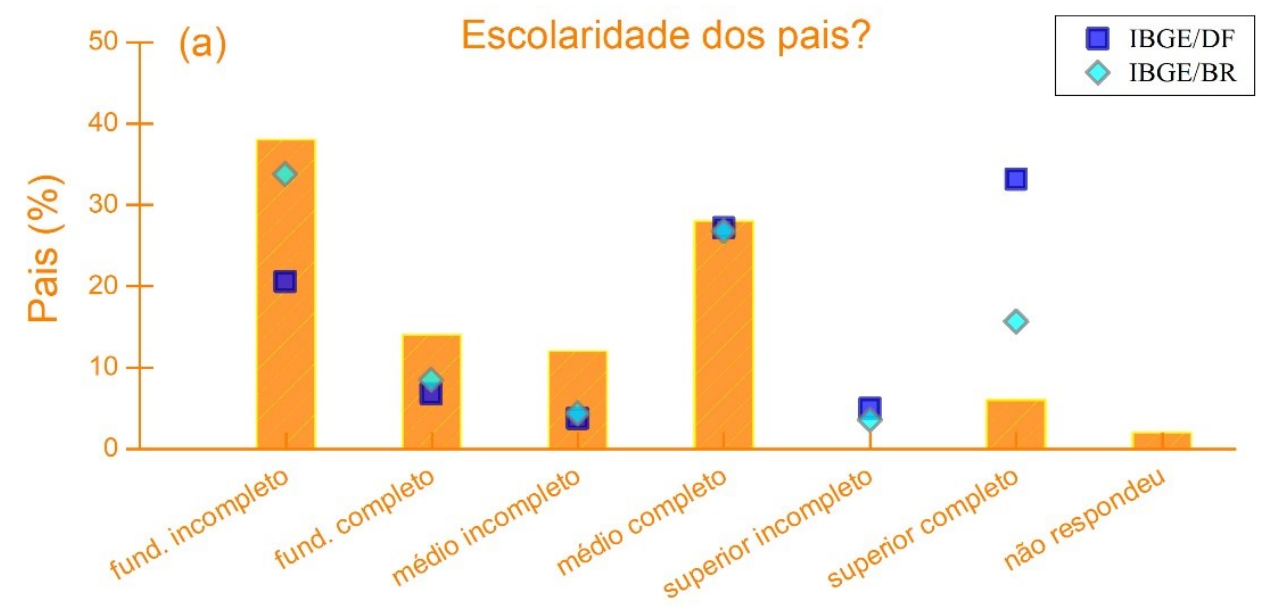

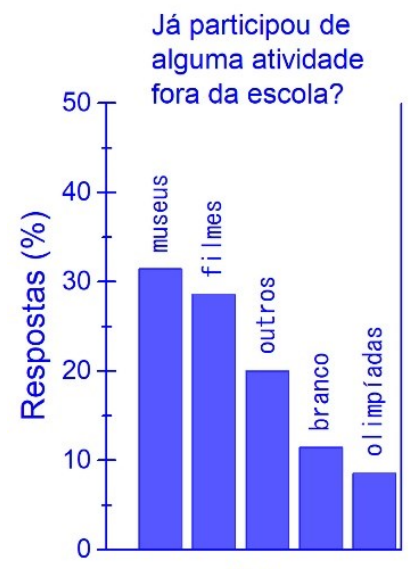

(b)

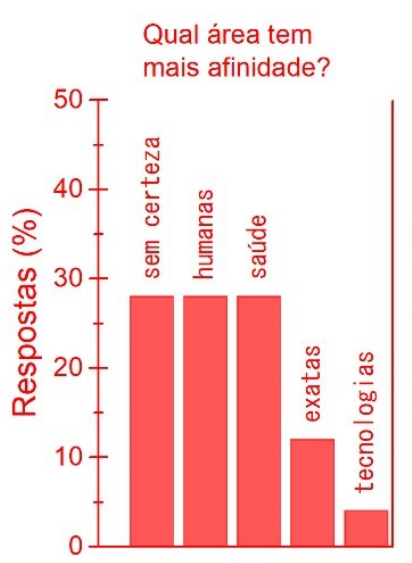

(c)

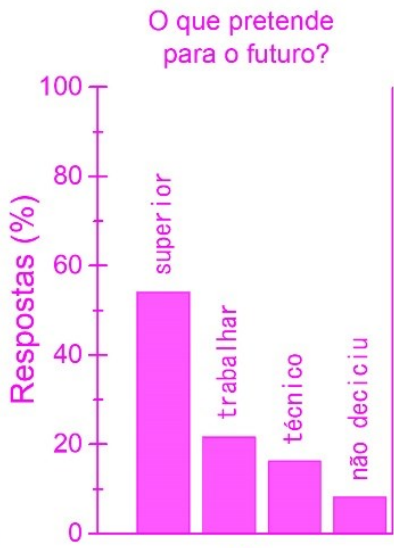

(d)

Fig. 1 - Resumo de algumas informações extraídas dos questionários aplicados após a visita. (a) Escolaridade média dos pais. Os símbolos quadrados (a) representam os dados do IBGE nacional e os simbolos diamante (1) representam os dados regionais. Esses dados têm variação significativa ao nível de confiança de 95\%. (b) Respostas sobre a participação de eventos de ciência fora do ambiente escolar. (c) Respostas sobre qual área tem mais afinidade e (d) o que pretende fazer no futuro.

Quando perguntados sobre a participação, fora da escola, em atividades que envolvessem ciência, as respostas centrais citaram visitas a museus e mostras de ciência (na UnB e centros culturais privados), participação nas Olimpíadas de Física e Matemática e assistir filmes de ficção científica. Tal situação parece indicar o que foi associado anteriormente sob a dimensão global familiar. Apesar dos alunos indicarem algum contato com atividades científicas, a percentagem encontra-se relativamente baixa no que tange ao total de alunos $(10,5 \%)$. A respeito das questões associadas à mídia, todos os filmes/seriados citados nas respostas são encontrados em plataformas on demand, que exigem serviços de internet ou TV a cabo, indicando que os alunos possuem acesso à informação. Chama atenção tal dado, visto que ainda que visitas aos museus tenham maior número de citações, as atividades midiáticas indicam papel importante para a formação cultural científica dos alunos. 
Esse debate já vem sendo tratado por alguns pesquisadores que indicam como o papel dos filmes, séries e desenhos animados influenciam a visão de ciência dos alunos (PIASSI; PIETROCOLA, 2009). Por outro lado, percebe-se que esse "estar no laboratório" pode ser uma experiência importante, visto a possibilidade de reconhecer e compreender elementos do fazer científico em dimensões mais próximas da realidade. Por esse motivo, destaca-se que $20 \%$ dos alunos responderam que nunca haviam participado de tais atividades, o que denota que a visita descrita anteriormente (sendo a primeira experiência) pode ser um importante meio complementar às aproximações anteriormente tratadas.

Depois disso, perguntamos com qual área das ciências eles têm mais afinidade. As áreas da Saúde e Humanas surgiram empatadas como as áreas de maior identidade entre os alunos, seguido de Ciências Exatas e Tecnologias, respectivamente. Tal representação pode estar associada ao forte apelo social de tais cursos, reconhecidos pela sua seletividade e papel importante na formação da elite brasileira (NOGUEIRA; NOGUEIRA, 2007). Também, foi encontrado no item "sem certeza" grande número de indicativo, que pode estar associado tanto ao perfil da faixa etária (17 anos) como fator determinante da fase juvenil (dúvidas e medos), como o afastamento dos jovens da formação no nível superior, fato que vem sendo percebido com a representatividade ainda pequena de alunos que finalizam o ensino básico e adentram o ensino superior nas carreiras tradicionais (SPARTA; GOMES; 2005).

A Fig.1(d) mostra as respostas dos alunos sobre suas ambições para o futuro. $\mathrm{O}$ ensino superior apresentou predominância nas respostas. Logo depois encontramos o trabalho, contudo essa resposta é citada em conjunto com o ensino superior e técnico, denotando que os alunos almejam adentrar ao mercado de trabalho como possível forma de manutenção de seus estudos e da vida familiar. Se, inicialmente, tal situação parece contradizer o que foi debatido anteriormente, cabe salientar, que as aspirações futuras dos jovens estão permeadas de desejos que refletem cursos que nem sempre condizem com as carreiras ditas tradicionais. Assim, pensar na formação no ensino superior como um futuro possível no Direito ou na Medicina não parece mais indicar o desejo dos jovens que procuram em formações distintas daquelas encontradas nos cursos tradicionais universitários.

\section{IV.2 Avaliação da visita}

A segunda parte do questionário abordou a avaliação da visita por parte dos alunos. O painel (a) da Fig. 2 mostra o panorama das respostas para a pergunta "o que mais gostou na visita?". A maior parte das respostas trouxe a tônica do despertar da curiosidade, a novidade ou ainda por terem aprendido mais sobre a temática. Uma parte das respostas cita ter gostado da organização e dinâmica da visita e ainda, uma pequena parte citou ter gostado do ambiente de estudos/criatividade e do entusiasmo dos pesquisadores em relatar os resultados de suas pesquisas. Em contrapartida, as respostas sobre o que menos agradou na visita se concentraram na crítica sobre o curto tempo da atividade, mesmo que essa tenha se estendido por aproximadamente 2 horas e meia. Cabe ressaltar que as críticas negativas nesse tipo de 
questionário vêm trazendo altos índices de não respostas. No caso do presente trabalho elas representam $40 \%$ entre nulos e nada. Ainda que se reconheça que os estudantes possam não ter nenhuma experiência negativa, pode existir certa dificuldade em avaliar (de modo comparativo) as visitas aos laboratórios científicos. Essa dimensão indica que aproximações com os cientistas têm sido pouco experienciadas pelos alunos, ou seja, há maior ênfase na oportunidade de estar nesses espaços sociais do que efetivamente nas experiências realizadas. Em outras palavras, significa que para os estudantes estar no laboratório já se tornou algo tão significativo que há pouco destaque para outras experiências e isso não lhes permite dizer se a ação vivenciada na atividade pode ser considerada negativa.

Outro aspecto que os impulsionou a criticar o "pouco tempo" de permanência foi a expectativa criada sobre a visita. A bem da verdade, a visita foi o fator motivacional durante todo o desenvolvimento da sequência, isso os fez pesquisar e estudar além do que foi pedido nas aulas, pois eles queriam impressionar os cientistas com suas indagações, tanto na palestra quanto na demonstração dos experimentos. Foi uma forma de mostrar o quanto estavam contentes por participar de algo proposto pela universidade. Eles sentiram-se acolhidos pela equipe e também importantes por terem aquele momento só para eles. Inclusive, após a visita, eles relataram que o trabalho mostrado pelos cientistas e suas aplicações os incentivou quanto a escolha de cursos no vestibular, voltados para o lado científico.

Para avaliar as escolhas feitas pela equipe na apresentação do LFC, perguntamos sobre qual área de pesquisa chamou mais atenção. Aplicações da nanotecnologia em medicina foi a área que mais chamou atenção dos estudantes. Essa resposta não é surpresa visto que grande parte dos estudantes se interessa pela área de ciências da saúde. Esse interesse também fica evidente na atividade realizada após a visita, ou seja, nas histórias em quadrinhos produzidas pelos alunos, já que três histórias destacam questões associadas à saúde, em especial, à cura de doenças como o câncer e a paralisia, além disso, o controle de situações desagradáveis ao bem-estar, como a podobromidrose (chulé).

Os resultados encontrados nessa categoria podem ser reconhecidos como importantes para a investigação ao construir uma ponte entre as respostas que se seguem e as práticas pedagógicas em sala de aula que antecederam a visita. Reconhecendo esse processo como ação escolar - visita ao laboratório, pode-se afirmar que a experiência vivenciada pelos estudantes foi impactada pela preparação na escola e, ao mesmo tempo, a atividade na escola impactou a interação no laboratório. Tais aspectos definem de modo substancial o quanto os resultados que se seguem devem ser compreendidos não somente como uma análise das respostas ao questionário, mas como representação das expectativas sociais, culturais e educacionais que foram geradas ao longo das atividades no contexto escolar. 


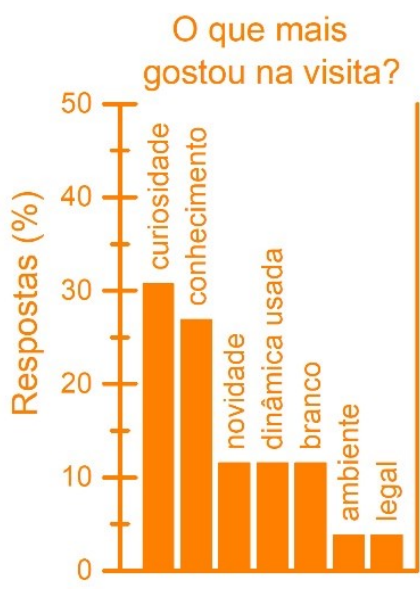

(a)

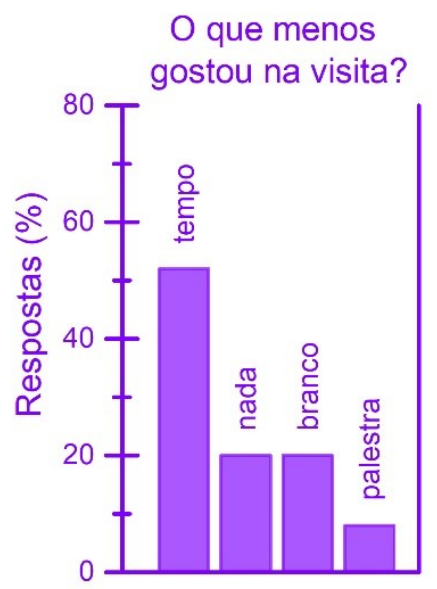

(b)

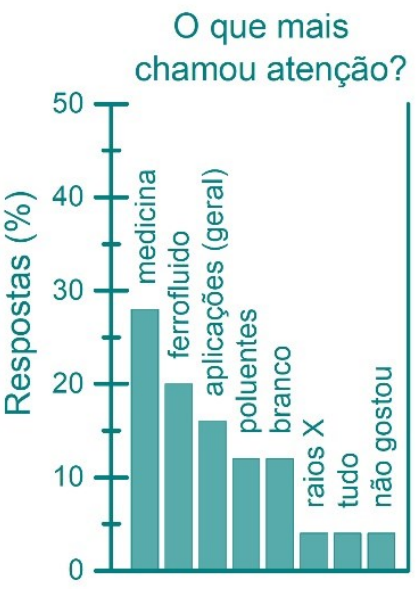

(c)

Fig. 2 - Resumo das respostas em relação à avaliação das atividades realizadas. (a) O que mais gostou na visita. (b) O que menos gostou na visita e (c) O que chamou mais atenção.

\section{IV.3 Compreensões sobre ciência e o trabalho do cientista}

Para a análise da parte final do questionário, cujo objetivo era compreender algumas concepções gerais dos jovens acerca da visita e sobre a ciência, foi pedido que os alunos respondessem de modo dissertativo a cinco perguntas relacionadas a: o que faz um cientista que desenvolve pesquisas em nanociência; qual a importância da nanociência para a sociedade e se essa deveria ser melhor informada sobre nanociência; se há necessidade de mais investimentos em pesquisas e quem deveria investir. De modo geral, as respostas dadas à essa terceira parte do questionário indicam que os alunos conhecem e reconhecem a atividade científica como algo importante para a sociedade.

Por exemplo, quando solicitados a explicar o que faz um cientista que desenvolve pesquisas em nanociência, doze alunos apresentaram contribuições para a sociedade, seis citaram aspectos estudados por eles sem fazer juízo de valor e onze não responderam à pergunta. Os dados a seguir exemplificam os dois grupos de respostas (contribuições e sem juízo de valor):

Ele estuda e aborda questões sobre como a nanociência pode ser usada, o que faz, quais os riscos e benefícios para todos os seres. (A1)

Ele está sempre se esforçando para melhorias para a sociedade, buscando curas para doenças, o que é muito importante. Estão sempre pesquisando e se dedicando a algo para ajudar as pessoas. (A4)

Pesquisa dos assuntos mais variados com o foco de ajudar a melhorar e a facilitar a vida humana. (A10)

Desenvolve pesquisas relacionadas a escalas de números muito pequenos. (A6) 
Ao questionar, em seguida, sobre a importância da sociedade saber sobre ciência, apenas um estudante afirmou que a população que não convive no meio científico não precisa saber sobre nanociência. Ainda que esse aluno não tenha justificado sua resposta, é interessante perceber a ciência como um saber possível de ser "ignorado" caso não haja nenhum tipo de relação pragmática com tal conhecimento. Dentre os alunos que responderam positivamente ao questionamento, ou seja, que reconhecem a importância de saber sobre nanociências, todos justificaram sua resposta destacando que se trata de um conhecimento que está presente na vida das pessoas ou é importante para a sociedade. Apenas dois alunos, cujas respostas são apresentadas a seguir, mencionaram que é necessário que a população em geral tenha conhecimentos sobre o assunto para avaliar riscos ou malefícios.

\section{Para ter esclarecimentos dos fatos, sejam eles bons ou ruins. (A18)}

\section{Para ela saber a importância e os riscos que ela tem. (A24)}

De acordo com a perspectiva defendida neste trabalho, mais do que avaliar impactos, a sociedade deve ser capaz de reconhecer as limitações e incertezas do conhecimento científico, além de seu comprometimento ideológico. Isso associa-se à necessidade de haver a democratização das decisões sobre o desenvolvimento científico-tecnológico. Ou seja, ao reconhecer limitações, incertezas e valores que influenciam as decisões tomadas no âmbito científico-tecnológico, passa-se a defender que elas não podem ficar restritas a técnicos, elas precisam ser compartilhadas com toda a população. Quanto a isso, destaca-se que apenas um aluno colocou que é importante que a sociedade conheça sobre o assunto "para que haja mais interessados em participar" (A10).

Nessa linha (de reconhecer a importância da ciência), apenas um aluno defende que o fim da profissão de cientista não impactaria em sua vida e todos colocam que são necessários mais investimentos nas áreas de ciência e tecnologia no Brasil. Sobre quem deveria investir, a maioria dos estudantes entende que essa ação cabe aos governos federal e estadual/distrital. É importante ressaltar que, como coloca Dagnino (2012) o estado brasileiro não investe pouco em ciência e tecnologia quando comparado com países de capitalismo avançado. Mas, ainda assim, os recursos são menores porque no caso brasileiro praticamente não há investimentos provenientes de empresas privadas. Apesar disso, somente cinco alunos entendem que as empresas deveriam investir em ciência e tecnologia no Brasil. O que nos mostra uma visão que ainda merece ser tratada nos contextos educacionais, reconhecendo a responsabilidade pelo desenvolvimento da ciência atrelado ao Estados e como um bem da sociedade civil.

Associado a esse reconhecimento sobre a importância da atividade científica, comparece a perspectiva salvacionista em torno da nanociência. Ou seja, ainda que implicitamente, os alunos demonstram acreditar que os problemas que a humanidade enfrenta, em particular os relacionados à cura de doenças, serão solucionados pelos avanços do desenvolvimento científico-tecnológico. Os excertos a seguir exemplificam essa compreensão: 
Nunca sabemos o dia de amanhã. Hoje estamos bem e com saúde e amanhã podemos pegar alguma doença sem cura, do qual cientistas estavam descobrindo a cura, e aí? Como iria ficar a população? Todos iriam morrer! (A4)

A nossa tecnologia está inovando e não trazendo coisas ruins, está trazendo beneficios e talvez em breve a cura. (A1)

Quanto mais investimentos, mais pesquisas serão elaboradas em prol da sociedade.

Essas respostas apontam os desafios associados às propostas educacionais que não vinculem de modo explícito os limites da ciência e da tecnologia, contudo, entendendo sua dimensão racional para o avanço da humanidade. Tais investimentos dos alunos na crença de que a ciência pode salvá-los de doenças e outros infortúnios sociais, demonstra que as propostas educativas precisam, constantemente, provocar a reflexão crítica dos jovens sobre os limites da atividade científica e tecnológica e que ela não está livre de valores.

Essa visão é ratificada nas histórias em quadrinhos produzidas pelos alunos ao final da intervenção e logo após a visita. Todas destacam que a nano trará benefícios inimagináveis e irá ajudar a humanidade. Apenas em duas histórias comparece uma preocupação quanto aos riscos desta nova ciência e tecnologia.

Essa crença nos feitos da ciência e da tecnologia tem sido problematizada no âmbito do movimento CTS, como discutido anteriormente. De acordo com Auler (2002) ela está associada a uma concepção de Ciência e Tecnologia neutras e pode ser considerada um mito construído historicamente. Com esses ideais, Auler e Delizoicov (2001) questionam as ações de democratização da ciência centradas na superação do déficit cognitivo da população e que defendem que é necessário que haja maior divulgação dos conhecimentos científicos. Para os autores, em vez deste "simples incremento quantitativo de conhecimentos divulgados" é necessário que as ações abarquem discussões consistentes sobre a produção e apropriação do conhecimento científico e tecnológico.

Neste caso, como descrito anteriormente, foram realizadas discussões que enfatizaram a influência de fatores políticos nas escolhas dos problemas de pesquisa do laboratório e na apropriação desse conhecimento. Porém, acredita-se que o encantamento dos pesquisadores com o trabalho contagiou os alunos, contribuindo para eles enfatizarem feitos positivos. Diante destes resultados, destacamos a importância de realizar as atividades em parceria com professores da educação básica para que as discussões possam ser ampliadas no contexto escolar e que sejam superados possíveis "encantamentos" provenientes do espaço de produção da ciência.

No caso desta intervenção, as discussões que ocorreram em sala de aula antes da visita enfatizaram conceitos científicos e aspectos associados à não neutralidade da ciência, incluindo as incertezas em torno da temática nano e influências ideológicas. Associado a isso, em 13 textos de 23 (produzidos antes da visita), foi possível localizar preocupações com o 
desconhecido e impactos negativos relacionados à ciência, como mostram os trechos a seguir:

Porém temos que lembrar que tudo que traz beneficios pode trazer riscos, pois a manipulação da matéria em escala pequena pode ocasionar problemas em muitos aspectos, pois não há onde armazenar o lixo tecnológico e a partir disso o meio ambiente fica bastante poluído afetando principalmente a saúde das pessoas. (T22)

Mas sempre tem o lado ruim da história, existem pessoas que usam disso para prejudicar o próximo, como a criação da bomba de hidrogênio, apesar dela nunca ter sido usada. E a humanidade não sabe as consequências disso em larga escala. (T12)

Mas, apesar disso, em 15 das 23 redações comparecem trechos que retratam uma visão próxima do salvacionismo, por enfatizar aspectos positivos da ciência. Os excertos a seguir exemplificam essas visões:

Após anos houve o desenvolvimento da pesquisa de prof. Xavier, onde foi efetivada a conquista da cura. Com ela inserida na sociedade, os casos de doenças foram diminuindo e prof. Xavier junto dos cientistas ficaram conhecidos por terem descoberto a cura, então ganharam o Prêmio Nobel, e o mundo ficou agradecido. (T7)

No meu ponto de vista os cientistas estão criando uma nova tecnologia mais avançada para evolução do mundo, e resolver os seus problemas com mais facilidades e mais eficaz para as pessoas. (T7)

Destacamos que esses textos foram produzidos antes da visita, após uma aula na qual foram discutidos aspectos sociais, políticos e econômicos associados às pesquisas. Entendemos que isso influenciou os alunos a mencionarem preocupações com o desconhecido e impactos negativos. Ao mesmo tempo, esta análise indica a presença de uma visão salvacionista, pois muitos alunos enfatizam que a ciência e a tecnologia, em algum momento, irão resolver os problemas que a humanidade enfrenta. Isso reforça o que afirmamos anteriormente e que tem sido amplamente difundido pela literatura da área, ou seja, que as visões associadas à ciência neutra são difíceis de serem superadas. Além disso, cabe destacar que, como coloca Auler (2002), se trata de um mito construído historicamente, sendo assim, uma atividade pontual como esta não será suficiente para superá-lo. Sendo assim, defendemos que são necessárias mais ações como esta.

Por outro lado, diante desses resultados, refletindo sobre as ações realizadas, localizamos uma série de fragilidades relacionadas às discussões desenvolvidas que, provavelmente, impactaram nas compreensões dos alunos. Dentre essas, entendemos que as reflexões em torno da visita e da atividade científico-tecnológica realizada/relatada pelos cientistas, foram insuficientes. Nesse sentido, reiteramos a necessidade de haver momentos de problematização antes e depois das vistas. Considerando os pressupostos da educação CTS, 
esses momentos precisam abarcar discussões sobre a produção e a apropriação do conhecimento científico e tecnológico. Nessa perspectiva, por exemplo, cabem reflexões sobre a origem e o direcionamento dado ao desenvolvimento científico-tecnológico e suas relações com a satisfação de necessidade humanas, associadas à verbalização dos valores internalizados nesse processo. Como mencionado, algumas discussões com essa ênfase foram realizadas antes da visita, porém, neste momento, após refletirmos sobre o processo, entendemos que foram insuficientes.

\section{Considerações finais}

O laboratório científico, o trabalho do cientista e o contexto de formação dos profissionais da ciência não são temas triviais. Para compreendê-los precisamos nos ancorar em estudos da antropologia (LATOUR; WOOLGAR; 1997), sociologia (OROZCO; CHAVARRO; 2010) e filosofia (CHALMERS, 1993). Pois requer não somente mobilizar saberes conceituais como, também, elementos culturais que visam promover aprofundamentos e reflexões críticas sobre o mundo da ciência e da tecnologia.

Como defendido ao longo deste artigo, a educação CTS pode fundamentar ações dessa natureza, ao permitir problematizações em torno da origem, concepção e direcionamento do conhecimento científico e tecnológico, contribuindo para a verbalização e superação de mitos associados à neutralidade da ciência. Isso, por sua vez, é importante para a formação de sujeitos capazes de compreender a transformar a realidade com a qual se encontram, tornando-a mais justa e igualitária.

Portanto, para a educação científica, cabe o desafio de promover tais conhecimentos, seja nos espaços formais ou nos espaços não formais de educação. E, ao contrário do que se espera na sociedade, demanda, também, que a responsabilidade seja dividida entre professores, pais e cientistas. Partindo de tais pressupostos que o presente artigo visou entender em que medida profissionais da ciência em parceira com professores da educação básica podem promover a formação de alunos da escola básica.

O que se tem observado em estudos anteriores (WATANABE, 2017) é que a dificuldade de fazer divulgação científica por cientistas está no que podemos considerar como o distanciamento desses profissionais (da ciência) na vida escolar. Assim, pode-se considerar que o papel do professor é fundamental para o desenvolvimento de ações que busquem a formação científica dos alunos de modo crítico e reflexivo como se espera na educação CTS. Soma-se a tal desafio, a questão social brasileira, marcadamente associada a desigualdades de cunho social e cultural que influenciam a qualidade das interações nos contextos estudados.

Nesse sentido, pode-se reconhecer que a ressonância entre os cientistas divulgadores e professores da educação básica podem dar importantes indicativos de espaços de cooperação para a produção de materiais tanto para a sala de aula como para melhoria das atividades de divulgação científica comprometidas com aspectos educacionais e sociais. Tais elementos podem ser reconhecidos nessa investigação através da preparação para a entrada no 
laboratório, a retomada das atividades na visita e a reflexão sobre o papel da ciência e da tecnologia na sociedade.

Os resultados apontaram para indícios dessa dimensão quando se percebe que a escola é um espaço privilegiado de diálogo com o mundo científico, propiciando aos alunos, tanto conhecer o lugar de trabalho do físico como, em alguns casos, a visita à universidade pública que almejam. Também, pode-se reconhecer as potencialidades desses espaços à medida que adentrar o laboratório científico pode permitir aos alunos debater e promover entendimentos sobre os limites da ciência no que tange ao debate ético e moral que a cerca. Ainda que tal perspectiva não seja explicitamente tratada nas visitas, elas se mostram abordagens potencialmente significativas para a formação dos alunos.

Por fim, cabe apontar que através dos resultados oriundos da análise do contexto sócio cultural e econômico dos sujeitos, percebemos o quão importante é esse tipo de ação. Em especial, devido à pequena aproximação dos estudantes com a cultura científica sob sua dimensão formal e seu interesse em dar continuidade aos estudos após o ensino médio. Revelando, portanto, elementos de formação dos estudantes que não perpassam apenas aspectos conceituais, mas se relacionam às aquisições do tipo capital cultural. Além disso, ainda que não seja objeto de investigação deste artigo, cabe colocar que a atividade repercutiu de forma mais ampla no ensino escolar, na medida em que contribuiu para a autoestima dos estudantes (que se sentiram "importantes" por terem sido recebidos por cientistas) e para que passassem a atribuir sentido ao conhecimento científico escolar, deixando de questionar, por exemplo, "para que serve isso que estamos estudando, professora?".

Essa ação também indica desafios associados à superação da suposta neutralidade da ciência por parte dos alunos, em especial, da visão salvacionista enfatizada neste artigo. Quanto a isso, entendemos que é preciso aumentar a frequência de atividades dessa natureza, sempre na perspectiva de articular escola básica e universidade, reconhecendo que ambas são responsáveis pela formação de cidadãos. Sobretudo, que essas atividades enfatizem problematizações em torno do processo de produção e apropriação do conhecimento científico e tecnológico, na perspectiva da Educação CTS.

\section{Agradecimentos}

Os autores agradecem às agências FAPDF, CAPES e CNPq pelo financiamento parcial de suas pesquisas. Estendemos o agradecimento a toda equipe do Laboratório de Fluidos Complexos da UnB que ajudou nesta pesquisa, tanto na organização da visita quanto na apresentação/visita às dependências do laboratório aos alunos. 


\section{Referências bibliográficas}

ARAÚJO, C. C. et. al. Ações de divulgação e popularização das Ciências Exatas via ambientes virtuais e espaços não formais de educação. Caderno Brasileiro de Ensino de Física, v. 34, n. 2, p. 649-668, ago. 2017.

AULER, D.; DELIZOICOV, D. Alfabetização científico-tecnológica para quê? Ensaio Pesquisa em Educação em Ciências, Belo Horizonte, v. 3, n. 2, p. 122134, dez. 2001.

AULER, D. Interações entre Ciência-Tecnologia-Sociedade no Contexto da Formação de Professores de Ciências. 2002. Tese (Doutorado) - UFSC, Florianópolis.

BARDIN, L. Análise de conteúdo. Edições 70: Portugal, 2008.

BEAUNE, J. C. La vulgarisation scientifique. L'Ombre des techniques. In: JACOBI, D. SCHIELE, B. (Orgs.) Vulgariser la science. Le procès de l'ignorance. Seyssel: Champ Vallon, 1988.

CAMPOS, A. F. C. MICHELS-BRITO, P. H.; SILVA, F. G.; CABREIRA GOMES, R.; GOMIDE, G.; DEPEYROT, J. Removal of direct yellow 12 from water using CTAB-coated core-shell bimagnetic nanoadsorbents. Journal of Environmental Chemical Engineering, v. 7, n. 2, p. 103031, 2019.

CHALMERS, A. F. O que é ciência afinal? Brasília: Brasiliense, 1993.

DAGNINO, R.; THOMAS, H.; DAVYT, A. El Pensamiento em Ciencia, Tecnología y Sociedad em Latinoamérica: uma interpretación política de su trayectoria. In: DAGNINO, R.; THOMAS, H. (Orgs.) Ciência, Tecnologia e Sociedade: uma reflexão latino-americana. Taubaté: Cabral Editora e Livraria Universitária, 2003.

DAGNINO, R. Entrevista com o professor titular do Departamento de Política Científica e Tecnológica da Unicamp, Renato Dagnino. [Entrevista concedida à] Agência Gestão CT\&I de Notícias. ABIPTI. Disponível em: <http://portal.abipti.org.br>. Acesso em: 29 out. 2012.

ENTRADAS, M; MARCELINO, J.; BAUER, M. W.; LEWESTEIN, B. Public communication by climate scientists: what, whith, whom and why? Climate Change, v. 254, n. 1, p. 69-85, 2019. DOI: 10.1007/s10584-019-02414-9

FREIRE, P. Extensão ou Comunicação? 4. ed. Rio de Janeiro: Paz e Terra, 1979. 
FREIRE, P. Pedagogia do Oprimido. 17. ed. Rio de Janeiro: Paz e Terra, 1987.

GARCÍA, M. I.; CEREZO, J. L.; LUJÀN, J. L. Ciência, tecnologia y sociedad. Uma introducción al estúdio social de la ciência y la tecnología. Madrid: Tecnos, 1996.

HU, S. Q.; LI, Z.F. Li; ZHANG, J.; ZHU, J. M. Engaging scientists in science communication: the effect of social proof and meaning. Journal of Cleaner Production, v. 170, p. 1044-1051, 2018.

JACOBI, D. La communication scientifique. Discours, figures, modèles. Grenoble: Pug, 1999.

LATOUR, B.; WOOLGAR, S. A vida de laboratório: a produção dos fatos científicos. São Paulo: Dumará, 1997.

LIMA, G. S.; GIORDAN, M. O movimento docente para o suo de divulgação científica em sala de aula: um modelo a partir da teoria da atividade. Revista Brasileira de Pesquisa em Educação em Ciência, v. 18, n. 2, 2018.

MERINO, N. S.; NAVARRO, D. H. T. Attitudes and perceptions of Conacyt researchers towards public communication of science and technology. Public Understanding of Science, v. 28, p. 85-100, 2019. DOI: 10.1177/0963662518781466

MORA, A. M. S. A divulgação da ciência como literatura. Rio de Janeiro: UFRJ, 2003.

NOGUEIRA, M. A.; NOGUEIRA, C. M. Bourdieu e a Educação. São Paulo: Autêntica, 2007.

OLIVEIRA, M. B. Considerações sobre a neutralidade da ciência. Trans/form/ação, São Paulo, v. 26, n. 1, p. 161-172, 2003.

OROZCO, L. A.; CHAVARRO, D. A. Robert K. Merton: la ciencia como institución. Revista de Estudos Sociais, n. 37, p. 143-162, 2010.

PIASSI, L. P.; PIETROCOLA, M. Ficção científica e ensino de ciência: para além do método de 'encontrar erros em filmes'. Educação \& Pesquisa, v. 35, n. 3, p. 525-540, 2009.

PILATI, V.; CABREIRA GOMES, R.; GOMIDE, G.; COPPOLA, G.; SILVA, F. G.; PAULA, F. L. O.; PERZYNSKY, R.; GOYA, G. F.; AQUINO, R.; DEPEYROT, J. Core/Shell Nanoparticles of Non-Stoichiometric $\mathrm{Zn}-\mathrm{Mn}$ and $\mathrm{Zn}-\mathrm{Co}$ Ferrites as 
Thermosensitive Heat Sources for Magnetic Fluid Hyperthermia. The Journal of Physical Chemistry C, v. 122, n. 5, p. 3028-3038, 2018.

ROSA, S. E.; STRIEDER, R. B. Não Neutralidade da Ciência-Tecnologia: verbalizações necessárias para potencializar a constituição de uma cultura de participação. Linhas Críticas, v. 25, 11 fev. 2019. Disponível em: <https://doi.org/10.26512/lc.v24i0.19701>.

SALÉM, S.; KAWAMURA, M. R. O texto de divulgação e o texto didático: conhecimento diferentes? In: ENCONTRO DE PESQUISADORES EM ENSINO DE FÍSICA, 1996, Belo Horizonte. Anais...

SPARTA, M; GOMES, W. Importância atribuída ao ingresso na educação superior por alunos do ensino médio. Revista Brasileira de Orientação Profissional, v. 6, n. 2, p. 45-53, 2005.

STRIEDER, R. B. Abordagem CTS na Educação Científica no Brasil: Sentidos e Perspectivas. 2012. Tese (Doutorado em Ensino de Ciências) - Instituto de Física, Universidade de São Paulo, São Paulo.

STRIEDER, R. B.; KAWAMURA, M. R. Educação CTS: parâmetros e propósitos brasileiros. Alexandria: Revista de Educação em Ciência e Tecnologia, Florianópolis, v. 10, n. 1, p. 27-56, maio 2017. DOI: https://doi.org/10.5007/1982-5153.2017v10n1p27.

WAGEnsberG, J. The "total" museum, a tool for social change. História, Ciência e Saúde, Manguinhos, v. 12, suplemento, p. 309-321, 2005.

WATANABE, G. Construíndo subsídios para a promoção da educação científica em visitas a laboratórios de pesquisa. 2017. Tese (Doutorado em Ensino de Ciências) Instituto de Física, Universidade de São Paulo, São Paulo.

(cc) EY-NC-ND Direito autoral e licença de uso: Este artigo está licenciado sob uma Licença Creative Commons. 